\title{
Accounting
}

\section{Integral evaluation as the basis of analytical support for managing the competitiveness of socially-oriented} retailers

\author{
Yaroslav Berezivskyi ${ }^{a^{*}}$, Vasyl Zbarsky ${ }^{b}$ and Anna Zbarskab
}

${ }^{a}$ Stepan Gzhytskyi National University of Veterinary Medicine and Biotechnologies Lviv, Ukraine

${ }^{b}$ National University of Life and Environmental Sciences of Ukraine, Ukraine

\begin{tabular}{l}
\hline C H R O N I C L E \\
\hline Article history: \\
Received: November 28, 2020 \\
Received in revised format: \\
December 282020 \\
Accepted: January 26, 2021 \\
Available online: \\
January 26, 2021 \\
\hline Keywords: \\
Enterprise competitiveness \\
Integral evaluation \\
Management \\
Development of retailers \\
Socially-oriented business
\end{tabular}

\section{Introduction}

Competitiveness is naturally considered to be one of the most generalized complex and systemic characteristics of an entity's functioning and development. These are not only the best qualitative or price characteristics of products, but also the productivity of the resource use, an increase in the business activity volume and the capitalization of a business unit, the realization of its economic potential, effective management of the development of business entities, in particular in retail trade (Apopiy, \& Dmetrenko, 2017; Uchid, \& Cook, 2005; Dunning, \& Lundan, 1998). Because of insufficiently managed processes of the internal market development, its monopolization, the complexity of an access to resources and markets, activity rights, fast tendencies to concentrate trade in networks, the tools and means of strengthening competitive positions of retail trade activity entities, in particular small and medium and especially social-oriented ones are becoming of high importance (Maksimov, Wang, \& Luo, 2017; Sipa, Gorzen-Mitka, \& Skibinski, 2015; Williams, 2007; Man, Lau, \& Chan, 2002).

\section{Literature review}

* Corresponding author.

E-mail address: berezivskyis@gmail.com (Y. Berezivskyi)

\begin{abstract}
The advantages of an integral approach to assessing the competitiveness of retailers are substantiated, which allows obtaining a more thorough and versatile informative base for making further managerial decisions to ensure the development of trading business. A new approach to the integral evaluation of the competitiveness of retailers is developed. The list of functional and structural components of intellivens was substantiated: marketing,financial and investment, material and technical, sequence of competitiveness assessment, which involves the alternate passage of the following stages: construction of an evaluation hierarchy, identification of the levels of the criterion importance, definition of a set of "local vectors" by evaluation criteria, conducting comparative evaluation of competing enterprises, hierarchical synthesis of alternative options for ensuring competitiveness. The analytic hierarchy process and used to form an information and analytical base. Using the Saaty's comparisons of the criteria of the retailers' competitiveness is formed. The Gallup Institute methodology is used to form the sample of enterprises. A matrix of rating positions of the sociallyoriented retailers is developed to enable evaluation. On the basis of the obtained results - analytical support of the policy(regarding the competitiveness level, state of security and coefficients of weight of its functional and structural components), the strategic principles of managing the competitiveness of socially-oriented retailers. A matrix of strategic decisions on managing the competitiveness of socially-oriented retailers is developed.
\end{abstract}

(C) 2021 by the authors; licensee Growing Science, Canada 
The formation of qualitative managerial decisions in the sphere of competitiveness ensuring is objectively based on the results of its evaluation. There are research findings where methodological approaches are used for such purposes, taking into account individual key indicators - enterprise competitiveness parameters (Ryzhkova \& Prosvirkin, 2015; Gunasekaran, Rai, \& Griffin, 2011; Dhungana, 2003). However, much more systematic conclusions can be drawn from the application of integral methodological approaches to assessing the level of the enterprise competitiveness (Odera, 2013; Jeppesen, 2007).

The problem of integral evaluation and formation of managerial approaches is especially relevant for socially-oriented (specializing in supplying goods to remote, rural, depressed territories, servicing low-income buyers) retailers, as it is of social and economic importance, solves in particular such tasks as the formation of purchasing funds of the population in less economically developed territories and stimulating, thus, consumer demand, meeting the needs of the population for goods and services, providing jobs to the population, investing in the economy, and supporting the development of related economic activities (Levytska, Mulska \& et al., 2020; Vasyltsiv, Lupak, \& Kunytska-Iliash, 2019; Boiko, 2017; Kajalo, \& Lindblom, 2010).

Therefore, the task of substantiating a new adaptive (for socially-oriented retailers) methodical approach to analyzing the level of enterprise competitiveness, its testing and processing the results for further justification of strategic managerial decisions in strengthening competitive positions of socially-oriented retailers (Ghosh, \& Whalley, 2008). It is of particular importance that a comprehensive approach be used in the analysis with the combination of characteristics of different competitiveness components - financial, social, material, personnel, etc. (Salickaite, \& Banyte, 2008; Saaty, 2008).

Integral evaluation mainly takes into account a wide range of criteria, which results in the justification of a number of problems and proposing rational means for solving them. At the same time, some scientific views are related to the narrow range of characteristics that are taken into account in integral evaluation. Thus, the enterprise competitiveness, including the retail sector, is linked to the level of economic security, innovation development, etc. (Havlovska, Pokotylova, Korpan, \& et al., 2019; Ilyash, Dzhadan, \& Ostasz, 2018; Varnaliy, Onishchenko, \& Masliy, 2016; Kumar, Mudambi, \& Gray, 2013).

\section{Materials and Methods}

To assess the competitiveness of retailers various methodological approaches that have their own characteristics (including partial or integral evaluation, components used, competitiveness criteria and indicators, data standardization algorithms) are used. Each methodological approach has strengths and weaknesses. However, an evaluation comprehensive result is only provided as a result of the integral analysis.

In virtually all the cases, a number of fundamental questions arise when applying integral evaluation (Gass, 1998; Lawrence, \& Gass, 2004; Saaty, 2008):

- What will the functional and structural components of competitiveness be like?

- How will the weight levels of these functional and structural components be calculated?

- What indices-indicators will be included in functional and structural components?

- How will the weight levels among the indices-indicators be calculated?

- Will purely quantitative, purely qualitative or a mixed indicator system be used?

- What are the sample (critical, etc.) values that will be compared with the actual values of the indices-indicators?

- Will statistical, actual for enterprises data, or the results of expert, sociological, and other types of research be used to formulate the information and analytical basis of calculations?

As a result of studying the special features of retailers' functioning, the identification of key components of increasing their business activity and ensuring its efficiency, the specifics of managing socially-oriented business units, in particular in remote less socially and economically developed territories, the list of the following functional features is substantiated: (1) marketing; (2) financial and investment; (3) material and technical; (4) intellectual and personnel; (5) innovation; (6) logistic; (7) social.

To determine the weight levels of the competitiveness functional and structural components, it is proposed to use the method of expert assessments, where the experts' judgments are evaluated by the scale of relative importance (Fig. 1). The following facts served as the arguments in favor of deciding whether to use an expert survey: firstly, a number of competitiveness components can be calculated on the basis of financial and statistical data of enterprises (financial and investment, material and technical, intellectual and personnel), but the others - only in the result of expert surveys (marketing, innovation, logistic, social) (Ilyash, Yildirim, Doroshkevych, \& et al., 2020); secondly, the weight levels of the competitiveness criteria can be immediately assessed by the expert survey results (Vasyltsiv, Irtyshcheva, Lupak, \& et al., 2020); thirdly, various indicators and components of the 
Y. Berezivskyi et al. /Accounting 7 (2021)

enterprise competitiveness can be reduced "to the common denominator" only as a result of the expert survey; fourthly, the importance of the external expert assessment is increasing for socially-oriented enterprises.

Definition

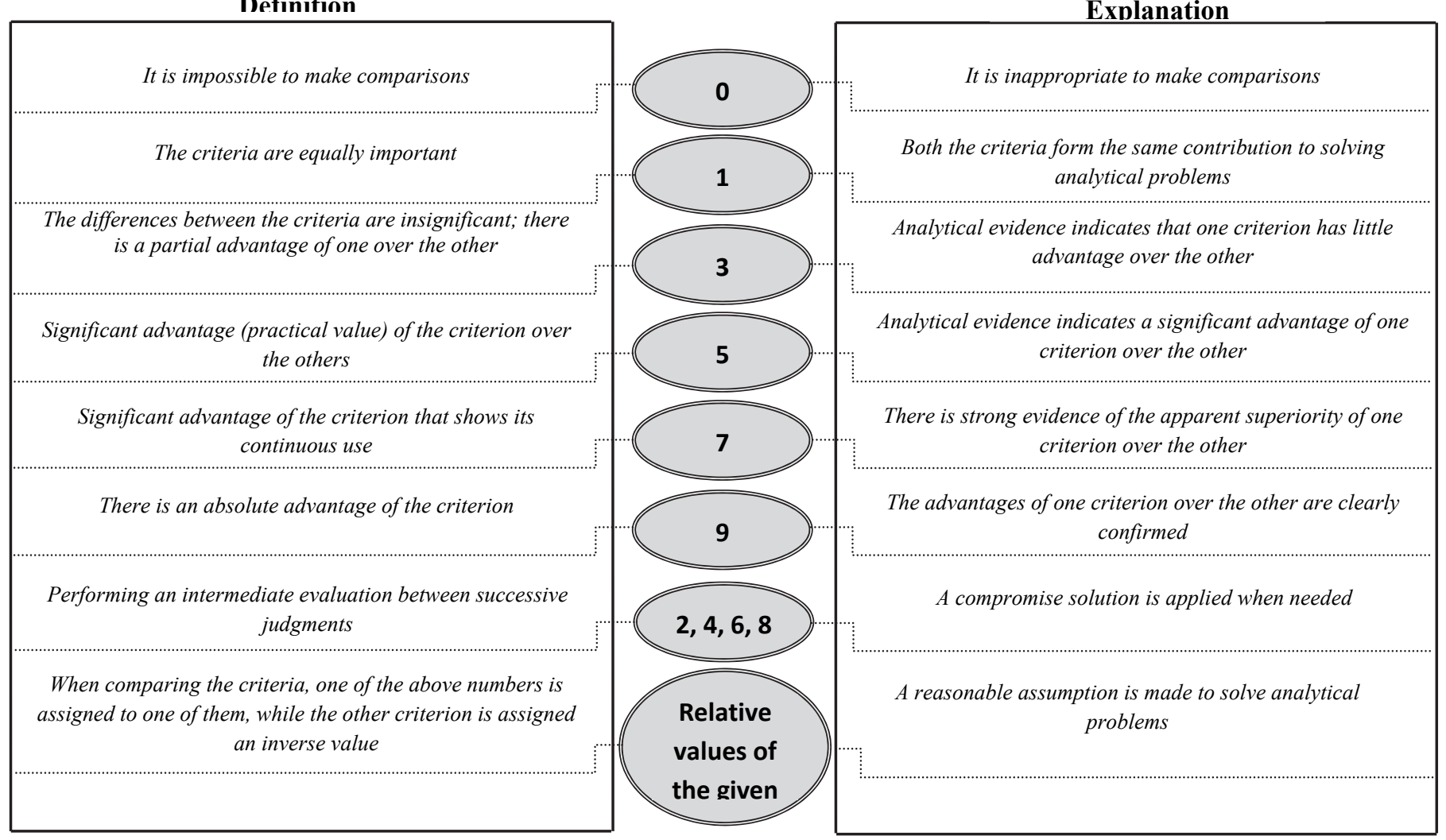

Fig. 1. Scale of assessing the relative importance of the competitiveness criteria Source: Developed by the author according to the source (Saaty, 2008)

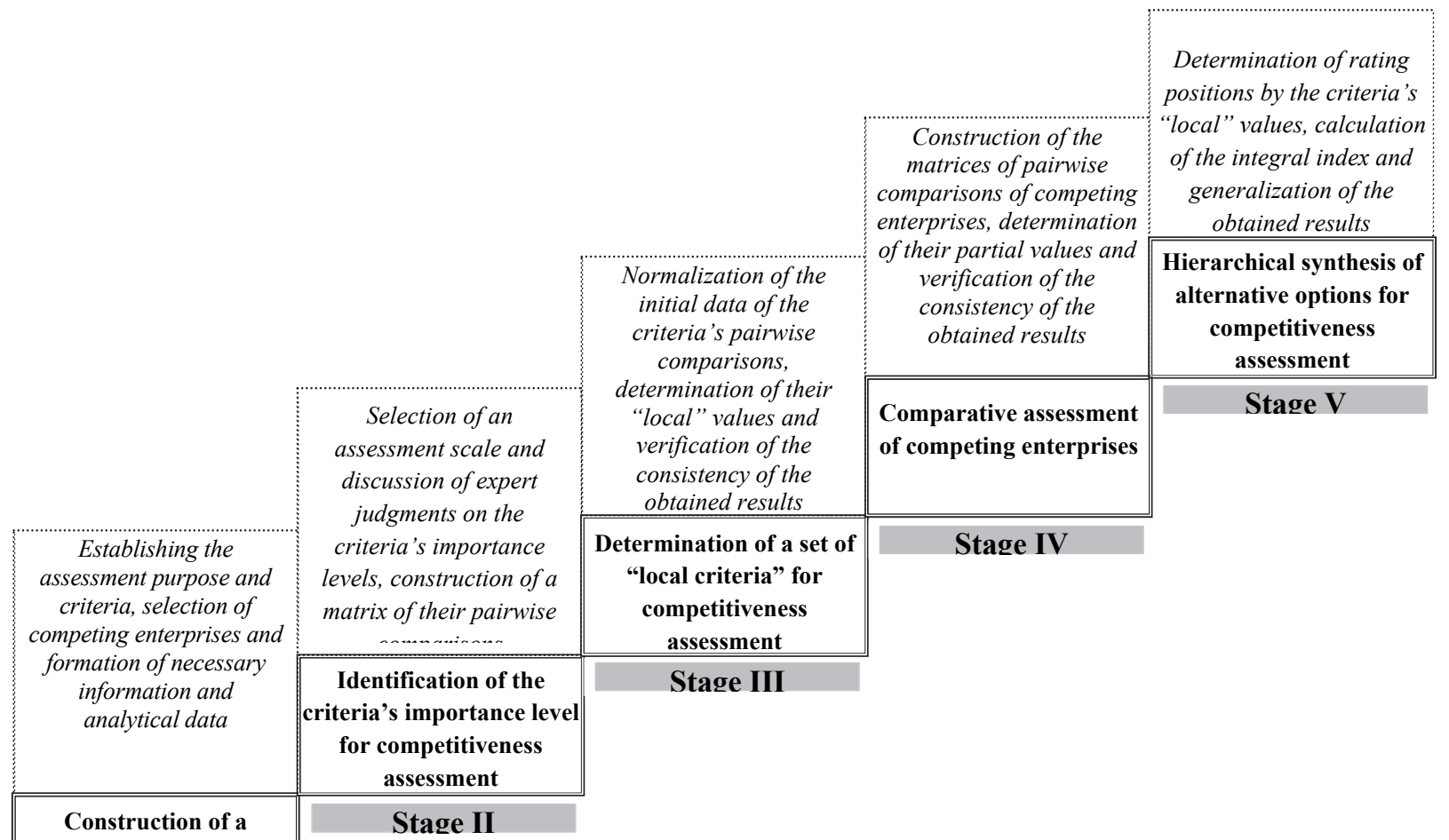

hierarchy of

competitiveness assessment

Fig. 2. Structural and logical scheme of the integral evaluation of the retailers' competitiveness Source: own processing

Stage I 
As an expert survey is used, it was decided not to use partial indices-indicators to harmonize the data, but to conduct the surveys on the characteristics of the competitiveness level in a consolidated way by functional and structural components. At the same time, this approach helped avoid the substantiation of the indicators' sample values. To enhance the approach credibility during the expert survey, the Delphi method is chosen, which allows the expert group to be represented more effectively and to process the questionnaire materials. The methodological sequence used to assess the competitiveness of socially-oriented retailers involves a step-by-step process (Fig. 2).

When constructing comparative matrices, the overall purpose and importance of each of the evaluation criteria are taken into account, which determines the degree of superiority and consistency between them. In this way, the matrix combines options and prerequisites that affect their formation and implementation while ensuring the trading enterprise's competitiveness (Table 1).

Table 1

Matrix of pairwise comparisons of the criteria of the retailers' competitiveness

\begin{tabular}{|c|c|c|c|c|c|c|c|}
\hline & Marketing & Social & $\begin{array}{c}\text { Material and } \\
\text { technical }\end{array}$ & Logistic & $\begin{array}{c}\text { Financial and } \\
\text { investment }\end{array}$ & Innovation & $\begin{array}{c}\text { Intellectual and } \\
\text { personnel }\end{array}$ \\
\hline Marketing & 1 & 5 & 7 & 9 & 3 & 3 & 3 \\
\hline Social & $1 / 3$ & 1 & 3 & $1 / 5$ & $1 / 3$ & $1 / 5$ & $1 / 5$ \\
\hline Material and technical & $1 / 5$ & $1 / 5$ & 1 & 5 & $1 / 3$ & 1 & $1 / 5$ \\
\hline Logistic & $1 / 7$ & 5 & $1 / 3$ & 1 & $1 / 7$ & $1 / 3$ & $1 / 7$ \\
\hline Financial and investment & 3 & 3 & 7 & 5 & 1 & 5 & 5 \\
\hline Innovation & $1 / 5$ & 5 & 3 & 3 & $1 / 5$ & 1 & $1 / 5$ \\
\hline Intellectual and personnel & $1 / 5$ & 5 & 5 & 3 & $1 / 5$ & 5 & 1 \\
\hline
\end{tabular}

Source: own research results

It is forecast that retailers in the process of ensuring competitiveness should first and foremost form marketing competitive potential, in particular the level of the criterion importance is substantially higher than logistic (preference degree 9), material and technical (7), social (5).

Achieving sufficient credibility and objectivity requires the normalization of primary information in the evaluation process. In particular, the calculation of the absolute value of the criterion importance for ensuring the retailer's competitiveness management, which is expressed numerically by the scale of relative importance, will involve the use of the following formula:

$$
P_{t}=\frac{\sqrt[n]{\prod_{g=1}^{n} \beta_{i g}}}{\sum_{i=1}^{n} \sqrt[n]{\prod_{g=1}^{n} \beta_{i g}}}
$$

where $P_{t}$ is the normalized (absolute) value of the importance degree of $t$-criterion of the retailer's competitiveness; $\beta_{i g}$ is a grouped element of the pairwise comparison matrix of expert judgments by $i$-ordinal row number of $g$-column of the pairwise comparison matrix $(i=1,2,3, \ldots, n ; g=1,2,3, \ldots, n) ; n$ is a set of elements of the matrix being evaluated. Integral calculations require complete consistency between the analytical data and, therefore, the obtained normalization results must be generalized. One way to summarize the matrix elements is to calculate the deviation of the maximum number $\left(\gamma_{\max }\right)$ from the ordinal one:

$$
\gamma_{\max }=\sum_{i=1}^{n}\left(P_{t} \times \sum_{i=1}^{n} \beta_{i g}\right),
$$

It is known that the pairwise comparison matrix is inversely symmetric and inequality $\gamma_{\max } \geq n$ must be satisfied for the calculation credibility. It should also be born in mind that a set of criteria for the retailers' competitiveness is heterogeneous and can be constantly changing, and this implies the evaluation of the degree of violation of the quantitative and ordinal homogeneity of the criteria $\left(D_{v}\right)$ :

$$
D_{v}=\frac{\gamma_{\max }-n}{n-1}
$$

Adhering to objectivity principles in the integral evaluation, it is necessary to realize the degree of significance of the agreed "local vectors" of matrix $\left(S_{d}\right)$ and, thus, to check the practical value of the expert proposals (Formula 4):

$$
S_{d}=\frac{D_{v}}{C_{r}}
$$

where $C_{r}$ is the temporal (random) consistency of the matrix" "local vectors". 
The final calculation of the Integral Competitiveness Index (ISC) involves comparing the "local vectors" of matrix $\left(V_{l}\right)$, taking into account the importance level of each criterion $\left(P_{t}\right)$, resulting in the partial values of the competitiveness "generalized vectors" $\left(G_{g c}\right)$ :

$$
I S C=\sum_{i=1}^{n} G_{g c}^{i}=\sum_{i=1}^{n}\left(V_{l}^{i} \times P_{k}^{i}\right)
$$

In this case, the growth of the rating position and competitive status of the trading entity will be evidenced by the approach of the integral indicator to a larger number.

\section{Results and discussion}

\subsection{Calculations of integral values and formation of the competitiveness rating of socially-oriented retailers}

The research of the competitiveness level was conducted on the basis of the 11 retailers (on the example of Ukraine), which are socially-oriented and operate in the rural areas of the country. The Gallup Institute methodology, based on certain criterion signs within the research scope, was used to justify the sample size of the retailers.

With respect to socially-oriented retailers, the following factors are attributed by the authors to such signs: activities in rural areas; a long period of retail business (more than five years), targeting low and medium price segments of the market, and organization of business in the form of small shops nearby.

It should be noted that, the size of retailers, as well as an increase in the volume of retail commodity turnover, including per employee, one $\mathrm{m}^{2}$ of retail space, turnover acceleration, as well as the improvement of financial parameters of the business development has become characteristic for the current stage of the socio-economic development of Ukrainian retailers (Shevchuk, Synchak, Zaverbnyj, \& Baranetska, 2019; Vasyltsiv, Lupak, \& Osadchuk, 2017; Vasyltsiv, \& Lupak, 2016). However, the economic prerequisites for ensuring the competitiveness of Ukrainian retailers both as a whole and those operating in remote, rural and depressed territories remain insufficient, as evidenced by the tendencies to deteriorate such key indicators of their financial status as own capital security, the investment ratio, the maneuverability ratio, the ratio of participation of working capital in the formation of current assets, the ratio of liability liquidity, the ratio of balance liquidity, the profitability of total and own capital, the enterprise's net profitability.

Table 2 summarizes the results of assessing the importance level of the "local vectors" in ensuring the retailers' competitiveness, obtained as a result of the survey of experts. Anticipatorily, it is possible to ascertain slightly higher influence on the integral value of the competitiveness of socially-oriented retailers of such areas of activity as marketing, finance and investments, the intelligence and human resources of business. Also it should be noted that the obtained value of the consistency of the experts' judgments $\left(S_{d}=0.012\right)$ is acceptable and confirms the statistical significance of the calculations.

\section{Table 2}

$\underline{\text { Results of assessing the importance level of the "local vectors" in ensuring the retailers' competitiveness }}$

\begin{tabular}{|c|c|c|c|c|c|}
\hline \multirow[b]{2}{*}{$\begin{array}{l}\text { Competitiveness } \\
\text { criteria }\end{array}$} & \multicolumn{5}{|c|}{ Indicators } \\
\hline & $\begin{array}{c}\text { Geometric mean values of } \\
\text { the criteria } \\
\left(\sqrt[n]{\prod_{g=1}^{n} \beta_{i g}}\right)\end{array}$ & $\begin{array}{l}\text { Absolute values of the } \\
\text { importance level of the } \\
\text { criteria }\left(P_{t}\right)\end{array}$ & $\begin{array}{l}\text { Values of the maximum } \\
\text { eigenvalue of the matrix } \\
\qquad\left(\gamma_{\max }\right)\end{array}$ & \multirow{8}{*}{$\begin{array}{l}\text { Indices of the } \\
\text { consistency of the } \\
\text { experts' judgments } \\
(D v)\end{array}$} & \multirow{8}{*}{$\begin{array}{c}\text { Relation of the } \\
\text { consistency of the } \\
\text { experts' judgments } \\
\left(S_{d}\right)\end{array}$} \\
\hline Marketing & 2.951 & 0.318 & 0.701 & & \\
\hline Social & 0.482 & 0.051 & 1.007 & & \\
\hline Material and technical & 0.519 & 0.060 & 1.061 & & \\
\hline Logistic & 0.388 & 0.043 & 1.077 & & \\
\hline $\begin{array}{c}\text { Financial and } \\
\text { investment }\end{array}$ & 2.925 & 0.309 & 0.902 & & \\
\hline Innovation & 1.087 & 0.102 & 1.081 & & \\
\hline \multirow[t]{2}{*}{$\begin{array}{l}\text { Intellectual and } \\
\text { personnel }\end{array}$} & 1.597 & 0.117 & 1.252 & & \\
\hline & & & 7.022 & 0.016 & 0.012 \\
\hline
\end{tabular}

Source: own research results

It should be added that the components that have the greatest impact on the competitiveness of socially-oriented retailers, provide it by more than $70.0 \%$, which is essential and needs to be taken into account in the formulation and implementation of the enterprise policy in the analyzed sphere. The result of the application of the author's method of integral evaluation of the competitiveness of socially-oriented retailers was the determination of the influence degree of each of the criteria on their competitive position (Formula 6), in particular, marketing (0.388), financial and investment (0.309) and intellectual and personnel (0.117) criteria determine the competitiveness the most: 
where $y$ is the retailer's competitiveness level; $x$ is criteria for ensuring competitiveness; $x_{1}-$ marketing; $x_{2}-$ social; $x_{3}-$ material and technical; $x_{4}-\operatorname{logistic} ; x_{5}-$ financial and investment; $x_{6}-$ innovation; $x_{7}-$ intellectual and personnel.

The results of the assessment of the economic and mathematical model of the retailers' competitiveness are presented in Table 3.

Table 3

Results of the stochastic assessment of the integrated model of the retailers' competitiveness

\begin{tabular}{lll}
\hline \multicolumn{1}{c}{ Indicators } & Value & \multicolumn{1}{c}{ Indicators } \\
\hline Determination coefficient & 0.8669 & F-statistics \\
Adjusted determination coefficient & 0.7643 & Standard deviation of the dependent variable \\
Standard regression error & 0.4727 & Hannan-Quinn information criterion \\
Logarithm of the maximum likelihood function & -2.9565 & Schwartz information criterion \\
Sum of the squared residual & 1.3539 & Akaike information criterion \\
p-value & 7.3672 & Durbin-Watson statistic \\
\hline
\end{tabular}

Source: own research results

As a result of passing the next stage of the methodological sequence of assessing the competitiveness of socially-oriented retailers, namely, generalizing the data obtained and drawing conclusions on the competitive environment (Table 4), it is established that, for example, a number of retailers are characterized by the predominance of social, material and technical and intellectual and personnel criteria, but, for example, are inferior to marketing and financial and investment components. This state of affairs cannot have a positive impact on the integral evaluation of their competitiveness.

Table 4

Ranking positions of the analyzed retailers by the integral competitiveness indicator in 2017-2019

\begin{tabular}{|c|c|c|c|c|c|c|c|c|c|c|c|}
\hline \multirow{2}{*}{$\begin{array}{l}\text { Criteria / } \\
\text { Indicators }\end{array}$} & \multicolumn{11}{|c|}{ Retailers } \\
\hline & (1) & (2) & (3) & (4) & $(5)$ & (6) & (7) & (8) & (9) & (10) & (11) \\
\hline \multicolumn{12}{|c|}{2017} \\
\hline$V_{l}$ & 0.0018 & 0.0041 & 0.0018 & 0.0119 & 0.1775 & 0.0010 & 0.0152 & 0.2381 & 0.0614 & 0.6871 & 0.0002 \\
\hline$P_{k}$ & 0.0006 & 0.0013 & 0.0006 & 0.0038 & 0.0571 & 0.0004 & 0.0049 & 0.0767 & 0.0198 & 0.2213 & 0.0002 \\
\hline \multirow{2}{*}{ B } & 0.0059 & 0.0918 & 0.0079 & 0.0176 & 0.3422 & 0.0026 & 0.0016 & 0.4771 & 0.1530 & 0.0684 & 0.0318 \\
\hline & 0.0002 & 0.0043 & 0.0004 & 0.0008 & 0.0161 & 0.0001 & 0.0001 & 0.0224 & 0.0072 & 0.0032 & 0.0014 \\
\hline \multirow{2}{*}{$\mathrm{C}$} & 0.3151 & 0.1985 & 0.0923 & 0.0025 & 0.0098 & 0.4068 & 0.1598 & 0.0012 & 0.0036 & 0.0102 & 0.0001 \\
\hline & 0.0167 & 0.0106 & 0.0049 & 0.0001 & 0.0005 & 0.0216 & 0.0085 & 0.0001 & 0.0002 & 0.0006 & 0.0001 \\
\hline \multirow{2}{*}{$\mathrm{D}$} & 0.0019 & 0.0014 & 0.0002 & 0.0229 & 0.2665 & 0.0008 & 0.0010 & 0.4616 & 0.2564 & 0.1357 & 0.0512 \\
\hline & 0.0001 & 0.0001 & 0.0001 & 0.0008 & 0.0096 & 0.0001 & 0.0001 & 0.0166 & 0.0092 & 0.0049 & 0.0018 \\
\hline \multirow{2}{*}{$\mathrm{E}$} & 0.0037 & 0.0066 & 0.0013 & 0.0113 & 0.2194 & 0.0026 & 0.0029 & 0.3059 & 0.0340 & 0.5099 & 0.1020 \\
\hline & 0.0011 & 0.0019 & 0.0004 & 0.0034 & 0.0649 & 0.0008 & 0.0008 & 0.0906 & 0.0101 & 0.1510 & 0.0302 \\
\hline \multirow{2}{*}{$\mathrm{F}$} & 0.0025 & 0.0058 & 0.0006 & 0.0890 & 0.4451 & 0.0014 & 0.0044 & 0.0852 & 0.4283 & 0.0857 & 0.0664 \\
\hline & 0.0002 & 0.0006 & 0.0000 & 0.0084 & 0.0422 & 0.0001 & 0.0005 & 0.0080 & 0.0407 & 0.0082 & 0.0064 \\
\hline \multirow{2}{*}{ G } & 0.0322 & 0.5009 & 0.0557 & 0.0036 & 0.0007 & 0.2892 & 0.2783 & 0.0028 & 0.0012 & 0.0036 & 0.0322 \\
\hline & 0.0049 & 0.0761 & 0.0085 & 0.0006 & 0.0001 & 0.0439 & 0.0422 & 0.0004 & 0.0002 & 0.0006 & 0.0049 \\
\hline $\begin{array}{c}\text { Integral } \\
\text { indicators }\end{array}$ & 0.0239 & 0.0949 & 0.0149 & 0.0180 & 0.1906 & 0.0671 & 0.0572 & 0.2148 & 0.0875 & 0.3898 & 0.0450 \\
\hline $\begin{array}{c}\text { Retailers' } \\
\text { ratings } \\
\end{array}$ & 9 & 4 & 11 & 10 & 3 & 6 & 7 & 2 & 5 & 1 & 8 \\
\hline \multicolumn{12}{|c|}{2018} \\
\hline \multirow{2}{*}{ A } & 0.0055 & 0.0124 & 0.0041 & 0.1066 & 0.1430 & 0.0053 & 0.0119 & 0.7150 & 0.0826 & 0.1066 & 0.0096 \\
\hline & 0.0018 & 0.0040 & 0.0013 & 0.0343 & 0.0461 & 0.0017 & 0.0038 & 0.2302 & 0.0266 & 0.0343 & 0.0031 \\
\hline \multirow{2}{*}{ B } & 0.4501 & 0.1163 & 0.1560 & 0.0014 & 0.0300 & 0.0388 & 0.3624 & 0.0134 & 0.0078 & 0.0223 & 0.0014 \\
\hline & 0.0211 & 0.0055 & 0.0073 & 0.0001 & 0.0014 & 0.0018 & 0.0170 & 0.0006 & 0.0004 & 0.0011 & 0.0002 \\
\hline \multirow{2}{*}{$\mathrm{C}$} & 0.0920 & 0.7002 & 0.0840 & 0.0050 & 0.0200 & 0.1740 & 0.1044 & 0.0070 & 0.0054 & 0.0054 & 0.0028 \\
\hline & 0.0049 & 0.0371 & 0.0044 & 0.0002 & 0.0011 & 0.0092 & 0.0055 & 0.0004 & 0.0002 & 0.0002 & 0.0001 \\
\hline \multirow{2}{*}{$\mathrm{D}$} & 0.0163 & 0.0031 & 0.0018 & 0.0378 & 0.5677 & 0.0019 & 0.0163 & 0.1967 & 0.1410 & 0.1892 & 0.0282 \\
\hline & 0.0006 & 0.0001 & 0.0001 & 0.0013 & 0.0204 & 0.0001 & 0.0006 & 0.0071 & 0.0050 & 0.0068 & 0.0010 \\
\hline \multirow{2}{*}{$\mathrm{E}$} & 0.0059 & 0.0918 & 0.0079 & 0.0176 & 0.3422 & 0.0026 & 0.0016 & 0.4771 & 0.1530 & 0.0684 & 0.0318 \\
\hline & 0.0018 & 0.0271 & 0.0024 & 0.0053 & 0.1013 & 0.0008 & 0.0005 & 0.1412 & 0.0452 & 0.0203 & 0.0094 \\
\hline \multirow{2}{*}{$\mathrm{F}$} & 0.0052 & 0.0258 & 0.0038 & 0.1338 & 0.2317 & 0.0017 & 0.0030 & 0.0576 & 0.6689 & 0.0430 & 0.0252 \\
\hline & 0.0005 & 0.0024 & 0.0004 & 0.0127 & 0.0220 & 0.0001 & 0.0002 & 0.0055 & 0.0636 & 0.0041 & 0.0024 \\
\hline \multirow{2}{*}{ G } & 0.0162 & 0.4387 & 0.0845 & 0.0054 & 0.0011 & 0.4368 & 0.1408 & 0.0042 & 0.0048 & 0.0156 & 0.0487 \\
\hline & 0.0025 & 0.0667 & 0.0128 & 0.0008 & 0.0001 & 0.0664 & 0.0214 & 0.0006 & 0.0007 & 0.0024 & 0.0074 \\
\hline $\begin{array}{c}\text { Integral } \\
\text { indicators }\end{array}$ & 0.0332 & 0.1429 & 0.0288 & 0.0548 & 0.1924 & 0.0802 & 0.0491 & 0.3856 & 0.1418 & 0.0692 & 0.0235 \\
\hline $\begin{array}{c}\text { Retailers' } \\
\text { ratings }\end{array}$ & 9 & 3 & 10 & 7 & 2 & 5 & 8 & 1 & 4 & 6 & 11 \\
\hline
\end{tabular}


Table 4

Ranking positions of the analyzed retailers by the integral competitiveness indicator in 2017-2019 (Continued)

\begin{tabular}{|c|c|c|c|c|c|c|c|c|c|c|c|}
\hline \multicolumn{12}{|c|}{2019} \\
\hline \multirow{2}{*}{ A } & 0.0182 & 0.0082 & 0.0061 & 0.1225 & 0.6364 & 0.0035 & 0.0913 & 0.2122 & 0.0734 & 0.0245 & 0.0048 \\
\hline & 0.0059 & 0.0026 & 0.0019 & 0.0395 & 0.2050 & 0.0011 & 0.0294 & 0.0683 & 0.0236 & 0.0079 & 0.0016 \\
\hline \multirow{2}{*}{ B } & 0.2736 & 0.0527 & 0.2119 & 0.0078 & 0.0948 & 0.1579 & 0.3671 & 0.0046 & 0.0082 & 0.0072 & 0.0136 \\
\hline & 0.0128 & 0.0025 & 0.0100 & 0.0004 & 0.0044 & 0.0074 & 0.0173 & 0.0002 & 0.0004 & 0.0004 & 0.0006 \\
\hline \multirow{2}{*}{$\mathrm{C}$} & 0.4381 & 0.0653 & 0.0097 & 0.4217 & 0.0281 & 0.2231 & 0.0072 & 0.0011 & 0.0019 & 0.0034 & 0.0002 \\
\hline & 0.0233 & 0.0035 & 0.0005 & 0.0223 & 0.0014 & 0.0119 & 0.0004 & 0.0001 & 0.0001 & 0.0001 & 0.0002 \\
\hline \multirow{2}{*}{ D } & 0.0041 & 0.0090 & 0.0053 & 0.0121 & 0.3156 & 0.0054 & 0.0157 & 0.5467 & 0.1358 & 0.1411 & 0.0090 \\
\hline & 0.0001 & 0.0004 & 0.0002 & 0.0005 & 0.0114 & 0.0002 & 0.0006 & 0.0197 & 0.0049 & 0.0050 & 0.0004 \\
\hline \multirow{2}{*}{$\mathrm{E}$} & 0.0158 & 0.0823 & 0.0071 & 0.0613 & 0.3067 & 0.0053 & 0.0068 & 0.4276 & 0.2376 & 0.0001 & 0.0493 \\
\hline & 0.0047 & 0.0244 & 0.0020 & 0.0181 & 0.0908 & 0.0016 & 0.0020 & 0.1266 & 0.0703 & 0.0001 & 0.0146 \\
\hline \multirow{2}{*}{$F$} & 0.0110 & 0.0064 & 0.0022 & 0.0737 & 0.4943 & 0.0059 & 0.0191 & 0.0952 & 0.4756 & 0.0085 & 0.0082 \\
\hline & 0.0011 & 0.0006 & 0.0002 & 0.0070 & 0.0469 & 0.0006 & 0.0018 & 0.0090 & 0.0451 & 0.0008 & 0.0007 \\
\hline \multirow{2}{*}{ G } & 0.3149 & 0.1355 & 0.1408 & 0.0090 & 0.0052 & 0.0469 & 0.4224 & 0.1050 & 0.0162 & 0.0030 & 0.0010 \\
\hline & 0.0479 & 0.0206 & 0.0214 & 0.0013 & 0.0008 & 0.0071 & 0.0642 & 0.0160 & 0.0025 & 0.0005 & 0.0002 \\
\hline $\begin{array}{c}\text { Integral } \\
\text { indicators }\end{array}$ & 0.0958 & 0.0546 & 0.0362 & 0.0890 & 0.3608 & 0.0299 & 0.1157 & 0.2399 & 0.1470 & 0.0148 & 0.0181 \\
\hline $\begin{array}{c}\text { Retailers' } \\
\text { ratings }\end{array}$ & 5 & 7 & 8 & 6 & 1 & 9 & 4 & 2 & 3 & 11 & 10 \\
\hline
\end{tabular}

(A) marketing; (B) social; (C) material and technical; (D) logistic; (E) financial and investment; (F) innovation; (G) intellectual and personnel Source: own research results

Such a general conclusion that can be drawn as a result of the analysis is interesting: if at the beginning of the analyzed period the difference between the integral values of the retailers' competitiveness was noticeable, in the end it was almost leveled, which is the evidence of:

- firstly, the competition complications;

- secondly, the use of virtually identical tools and strategies for the competition by the retailers;

- thirdly, the relevance of the formation of new approaches and strategies in the development, diversification of business, and the use of their own specific competitive advantages.

\subsection{Substantiation of the system of strategic management for strengthening the competitiveness of socially-oriented retailers}

Socially-oriented retailers operate in an open competitive environment. Therefore, in ensuring their competitiveness as a characteristic of the ability to survive in the market and to force their direct competitors out of it, retailers, despite the involvement of internal forces, should also use the opportunities that they can attract from the external environment. It is about retailers' participation in the initiation and implementation of programs to stimulate the socio-economic development of the territory in which they operate, the formation of various types of cooperative associations within the vertical and horizontal integration, the diversification of forms and systems of merchandise distribution, forms and formats of trade, the development of the institutional basis of competitiveness ensuring. The measures in these areas will simultaneously increase the loyalty level of both the consumer and population living in the territory where the enterprise operates.

Using the method of strategic analysis, the strategic priorities for forming the competitiveness of socially-oriented retailers in such areas as marketing, financial and investment, material an technical, intellectual and personnel, innovation, logistic and social are identified (Figure 3).

It should be emphasized that the implementation of an effective policy of strengthening the competitiveness of socially-oriented retailers requires measures to be taken in all of the identified areas. However, the type and form of strategic behavior of retailers may vary depending on financial resources, the effectiveness of their financial and economic activity at the current stage of functioning and development, the purchasing power of the population, other factors, including external factors and conditions. 


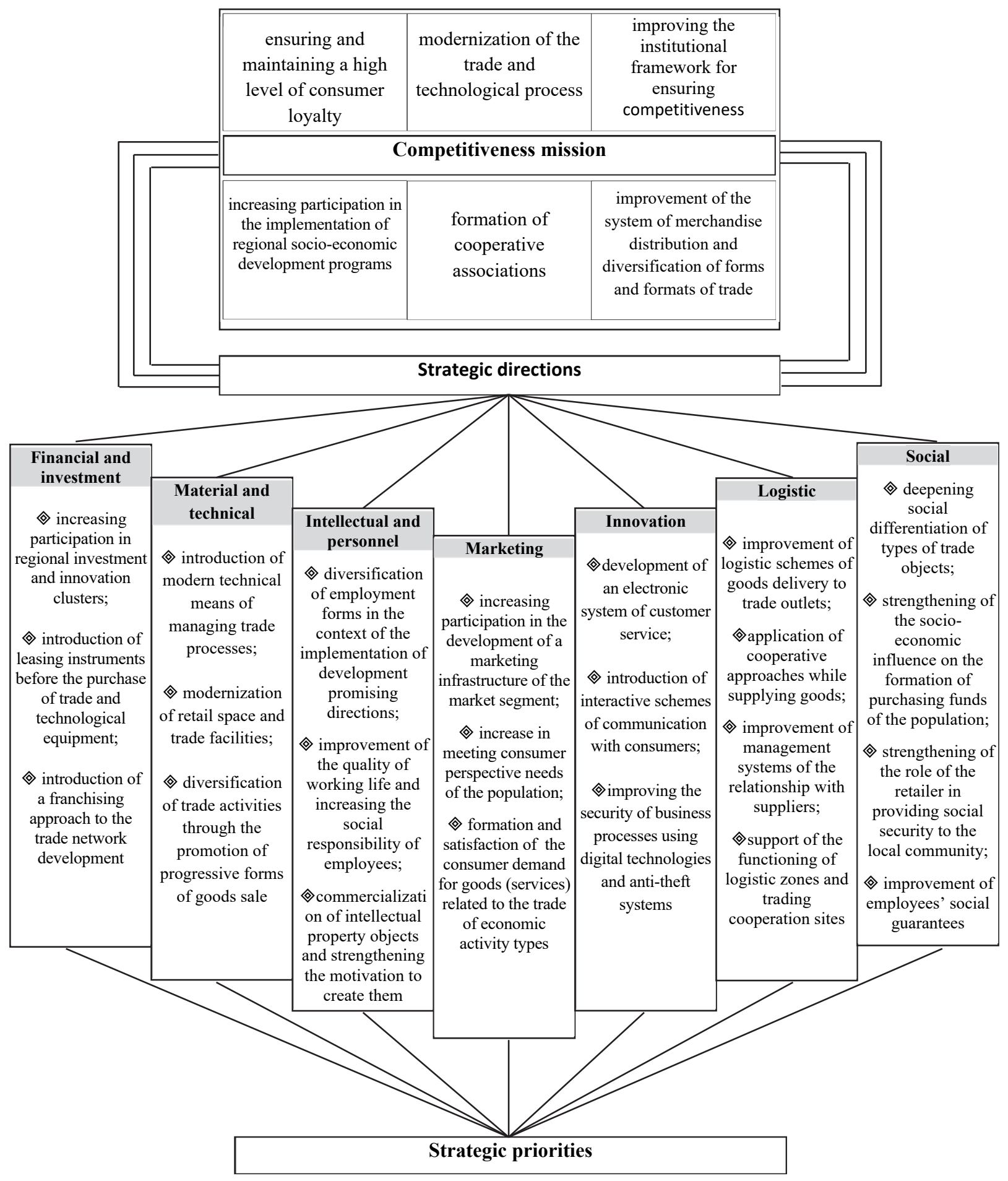

Fig. 3. Strategic principles of the formulation of the policy for ensuring competitive advantages of socially-oriented retailers Source: own processing

The factors of purchasing power of the population as well as the level of business commercial specialization (Fig. 4) should be considered critical in the context of ensuring the competitiveness of retailers operating in economically weaker territories.

On the other hand, it should be noted that the policy of ensuring the retailer's competitiveness is of a long-term nature, since its implementation requires financial and resource support. 


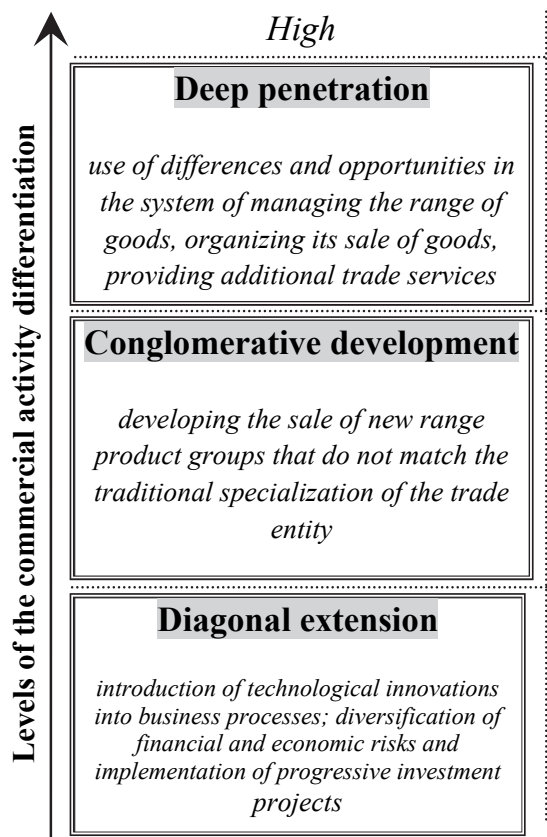

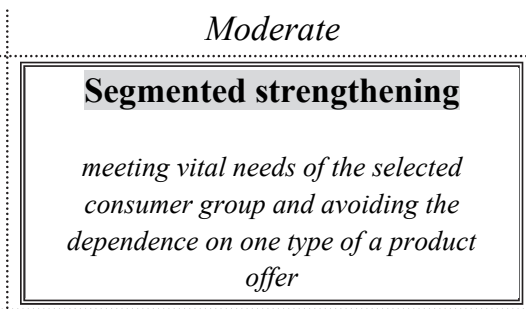
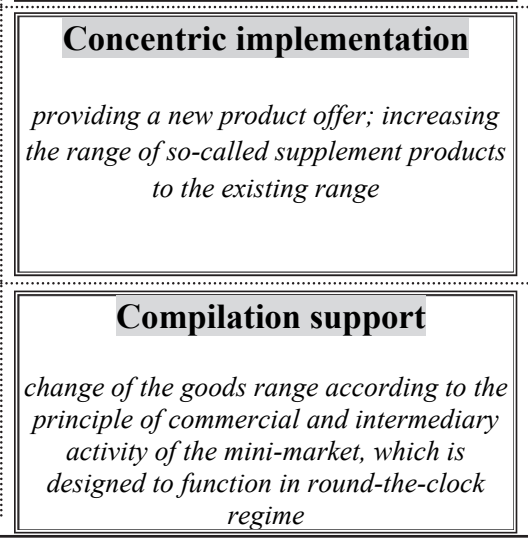

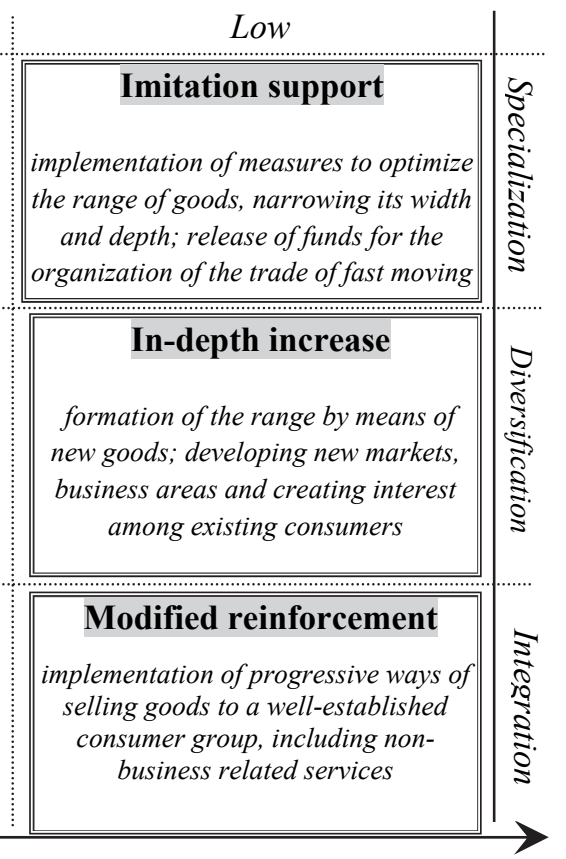

Level of the population demand solvency

Fig. 4. Matrix of the choice of strategic decisions on the competitiveness management of the objects of socially-oriented retailers Source: own processing

Initially, the leaders of socially-oriented retailers should focus on enhancing their competitive advantages, first of all, depending on the location of retail outlets (Figure 5). Thus, it is important for retailers operating only in rural settlements to optimize their product range and price diversification; for retailers operating in suburban areas - to increase the speed of customer service, and for retailers developing their business to the level of urban settlements - to work on the specialization and formation of a unique product offer.

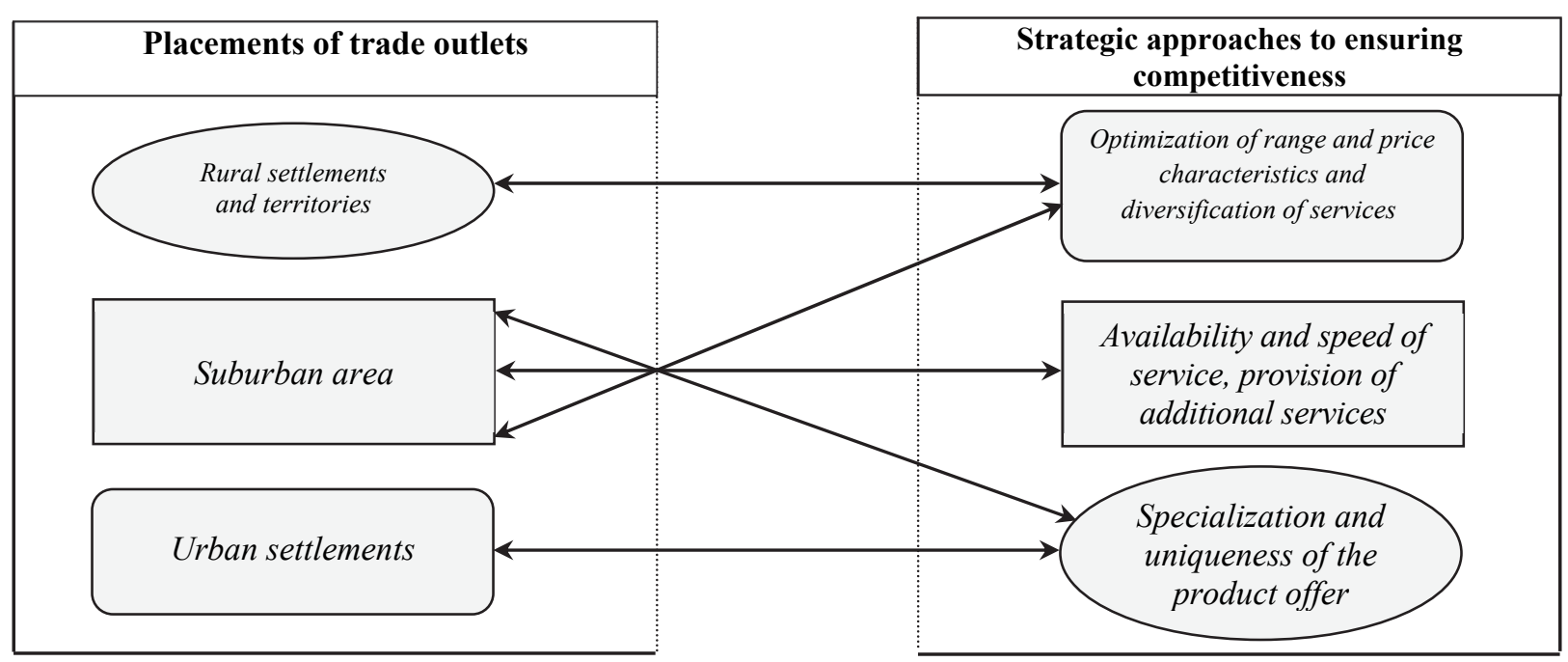

Fig. 5. Matrix of the choice of strategic decisions on ensuring competitiveness depending on the location of socially-oriented retailers

Source: own processing

Strategic management of strengthening the competitiveness of socially-oriented retailers initially requires the formation of a competitiveness mission as ensuring a high level of consumer loyalty by meeting their current and formulating prospective needs, the coordination of the directions of the development of the retailer's business processes with them. Such a mission (a strategic policy objective) obviously concerns the strengthening of all the components and the integral level of the retailer's competitiveness. But the peculiarity here is that competitiveness is a dynamic characteristic, therefore, it requires constant work on its formation, provision and support. Moreover, the potential for competitiveness is much higher for the retailers pursuing the policy of strengthening competitiveness not in one particular direction, or even financial and economic activity in general, 
but considering their business more broadly - as a complex of all the available and potential resources and opportunities that can be attracted and used.

Given these circumstances, the competitiveness mission of socially-oriented retailers should lie in transforming them into competitive complexes of the dynamic development. For this purpose it is necessary to act in the direction of the improvement of intellectual and personnel support, the informatization of all the internal and external business processes, the improvement of the system of communication with consumers and counterparties.

\section{Conclusion}

The retailer's competitiveness is a complex, systematic and dynamic category, which comprehensively characterizes the state of its functioning and development through the prism of the ability to win in the competitive struggle with the enterprises of a similar type of economic activity and the specialization for the consumer's loyalty and purchasing funds.

Thus, analyzing the level of the retailer's competitiveness gives grounds for conclusions regarding the potential for further development and strengthening of the retailer's competitive positions in the consumer market. For such purposes, the results of the integral analysis of the retailer's competitiveness level are particularly applicable, since they serve as a more systematic and sound information and analytical basis - ensuring the formation of better and more effective managerial decisions for further business development.

Retailers are objectively characterized by their own special features (grounded primarily by the specificity of this type of economic activity), in particular those that specialize in operating in remote territories and are socially-oriented. Therefore, the research proposes the author's approach to the integral evaluation of the competitiveness level, taking into account the special features of socially-oriented retailers' functioning. The following structural and functional competitiveness components are foreseen: marketing, financial and investment, material and technical, intellectual and personnel, innovation, logistic and social. The competitiveness of the 11 retailers operating in the rural territories of Ukraine is evaluated. The calculations of the coefficients of the component weight and component characteristics of the retailers' competitiveness are carried out using an expert survey.

The use of an integral evaluation technique made it possible to ensure the concept integrity about the competitiveness level (just as a measure, not a state) and to determine the influence degree of each of the criteria on the retailer's position in the competitive environment. The advantages of integral evaluation also include the ability to track changes in the competitiveness level in dynamics, to compare the competitiveness level among the analyzed retailers, to identify the factors that determine the overall competitiveness to a greater extent, and to monitor trends in the coefficients of the factors' weight

Based on the obtained results, the competitiveness mission of the socially-oriented retailers as a guarantee and maintenance of the high level of consumer loyalty for the transformation of business into competitive complexes of the dynamic development is substantiated. For this purpose, it is necessary to act in the direction of the improvement of intellectual and personnel support, the informatization of all the internal and external business processes, the improvement of the system of communication with consumers and counterparties.

Thus, integral evaluation serves as a strategic basis for analytical support for managing the competitiveness of socially-oriented retailers, which is especially important in the context of the need to level the socio-economic development of the country's territories, to eliminate the critical gaps of depressed territories.

\section{References}

Apopiy, V., \& Dmytrenko, I. (2017). Increasing competitiveness of retail trade on the basis of structural transformations. Journal of Research on Trade. Management and Economic Development, 4(2), 80-88.

Boiko, V. (2017). Diversification of Business Activity in Rural Areas as a Risk Minimization Tool of Economic Security. Management Theory and Studies for Rural Business and Infrastructure Development, 39(1), 19-32. https://doi.org/10.15544/mts.2017.02

Dhungana, B. P. (2003). Strengthening the competitiveness of small and medium enterprises in the globalization process: prospects and challenges. Investment Promotion and Enterprise Development Bulletin for Asia and the Pacific, 1, 1-32.

Dunning, J. H., \& Lundan, S. M. (1998). The geographical sources of competitiveness of multinational enterprises: an econometric analysis. International Business Review, 7(2), 115-133. https://doi.org/10.1016/S0969-5931(98)00001-8

Gass, S.I. (1998). Tournaments, transitivity and pairwise comparison matrices. Journal of the Operational Research Society, 49, 616-624. https://doi.org/10.1057/palgrave.jors.2600572

Ghosh, M., \& Whalley, J. (2008). State owned enterprises, shirking and trade liberalization. Economic Modelling, 25(6), 12061215. https://doi.org/10.1016/j.econmod.2008.03.005 
Y. Berezivskyi et al. /Accounting 7 (2021)

Gunasekaran, A., Rai, B. K., \& Griffin, M. (2011). Resilience and competitiveness of small and medium size enterprises: an empirical research. International Journal of Production Research, 49(18), 5489-5509. https://doi.org/10.1080/00207543.2011.563831

Havlovska, N., Pokotylova, V., Korpan, O., Rudnichenko, Ye., \& Sokyrnyk, I. (2019). Modeling of the process of functioning of the mechanism of economic security of foreign economic activity of enterprise taking into account weak signals and identification of risks and threats. International Journal of Scientific \& Technology Research, 8(12), 2216-2522.

Ilyash, O., Dzhadan, I., \& Ostasz, G. (2018). The influence of the industry's innovation activities indices on the industrial products' revenue of Ukraine. Economics and Sociology, 11(4), 317-331. https://doi.org/10.14254/2071-789X.2018/11-4/21

Ilyash, O., Yildirim, O., Doroshkevych, D., Smoliar, L., Vasyltsiv, T., \& Lupak, R. (2020). Evaluation of enterprise investment attractiveness under circumstances of economic development. Bulletin of Geography. Socio-economic Series, 47, 95-113. https://doi.org/10.2478/bog-2020-0006

Jeppesen, S. (2007). Enhancing competitiveness and securing equitable development: Can small, micro, and medium-sized enterprises (SMEs) do the trick? Development in Practice, 15(3-4), 463-474. https://doi.org/10.1080/09614520500076100

Kajalo, S., \& Lindblom, A. (2010). How retail entrepreneurs perceive the link between surveillance, feeling of security, and competitiveness of the retail store? A structural model approach. Journal of Retailing and Consumer Services, 17(4), 300305. https://doi.org/10.1016/j.jretconser.2010.03.001

Kumar, V., Mudambi, R., \& Gray, S. (2013). Internationalization, Innovation and Institutions: The 3 I's Underpinning the Competitiveness of Emerging Market Firms. Journal of International Management, 19(3), $203-206$. https://doi.org/10.1016/j.intman.2013.03.005

Lawrence, B., \& Gass, S. I. (2004). Exercises for Teaching the Analytic Hierarchy Process. INFORMS Transactions on Education, 4(2), 1487-1497. https://doi:10.1016/S0305-0548(02)00188-0

Levytska, O., Mulska, O., Ivaniuk, U., Kunytska-Iliash, M., Vasyltsiv, T., Lupak, R. (2020). Modelling the Conditions Affecting Population Migration Activity in the Eastern European Region: The Case of Ukraine. Tem Journal, 9(2), 507-514. https://doi.org/10.18421/TEM92-12

Maksimov, V., Wang, S. L., \& Luo, Y. (2017). Reducing poverty in the least developed countries: The role of small and medium enterprises. Journal of World Business, 52(2), 244-257. https://doi.org/10.1016/j.jwb.2016.12.007

Man, T. W.Y., Lau, T., \& Chan, K. F. (2002). The competitiveness of small and medium enterprises: A conceptualization with focus on entrepreneurial competencies, Journal of Business Venturing, 17(2), 123-142. https://doi.org/10.1016/S08839026(00)00058-6

Odera, O. (2013). Analysis of retail marketing strategies on organizational competitiveness. International Journal of Management \& Information Technology, 3(2), 43-46. https://doi.org/10.24297/ijmit.v3i2.1366

Ryzhkova, E., \& Prosvirkin, N. (2015). Cluster initiatives as a competitiveness factor of modern enterprises. European Research Studies Journal, 18(3), 21-30.

Saaty, T. L. (2008). Relative Measurement and its Generalization in Decision Making: Why Pairwise Comparisons are Central in Mathematics for the Measurement of Intangible Factors - The Analytic Hierarchy / Network Process. Review of the Royal Spanish Academy of Sciences, Series A, Mathematics, 102(2), 251-318

Salickaite, R., \& Banytè, J. (2008). Successful Diffusion and Adoption of Innovation as a Means to Increase Competitiveness of Enterprises. Engineering Economics, 1(56), 48-56.

Shevchuk, V. O., Synchak, V., \& Zaverbnyj, A. S., Baranetska O. V. (2019). Determinants of the current account balance and output in Ukraine. Financial and Credit Activity: Problems of Theory and Practice, 30, $186-195$. https://doi.org/10.18371/fcaptp.v3i30.179532

Sipa, M., Gorzeń-Mitka, I., \& Skibiński, A. (2015). Determinants of Competitiveness of Small Enterprises: Polish Perspective. Procedia Economics and Finance, 27, 445-453. https://doi.org/10.1016/S2212-5671(15)01019-9

Uchid, Y., \& Cook, P. (2005). The effects of competition on technological and trade competitiveness. The Quarterly Review of Economics and Finance, 45(2-3), 258-283. https://doi.org/10.1016/j.qref.2004.12.003

Varnaliy, Z., Onishchenko, S., \& Masliy, A. (2016). Threat prevention mechanisms of Ukraine's economic security. Economic Annals-XXI, 159(5-6), 20-24. https://doi.org/10.21003/ea.V159-04

Vasyltsiv, T. G., Lupak, R. L., \& Kunytska-Iliash, M. V. (2019). Social Security of Ukraine and the EU: aspects of convergence and improvement of migration policy. Baltic Journal of Economic Studies, 5(4), 50-58. https://doi.org/10.30525/22560742/2019-5-4-50-58

Vasyltsiv, T., \& Lupak, R. (2016). Strategic priorities of state structural policy of import substitution in Ukraine. Actual Problems of Economics, 1(175), 52-60.

Vasyltsiv, T., Irtyshcheva, I., Lupak, R., Popadynets, N., Shyshkova, Y., Boiko, Y., \& Ishchenko, O. (2020). Economy’s innovative technological competitiveness: Decomposition, methodic of analysis and priorities of public policy. Management Science Letters, 10(13), 3173-3182. https://doi.org/ 10.5267/j.msl.2020.5.004

Vasyltsiv, T., Lupak, R., \& Osadchuk, Yu. (2017). Assessment of the level of penetration of import dependence in the context of the import substitution policy in Ukraine. Economic Annals-XXI, 167(9-10), 13-17. https://doi.org/10.21003/ea.V167-03

Williams, D. A. (2007). Competitiveness of small enterprises: Insights from a developing economy. The Round Table. The Commonwealth Journal of International Affairs, 96(390), 347-363. https://doi.org/10.1080/00358530701463840 


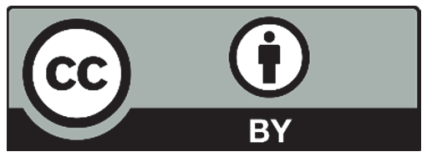

(C) 2021 by the authors; licensee Growing Science, Canada. This is an open access article distributed under the terms and conditions of the Creative Commons Attribution (CC-BY) license (http://creativecommons.org/licenses/by/4.0/). 